\title{
APROXIMACIÓN TEÓRICA AL ESTUDIO SOCIOLÓGICO DE LA ANOREXIA Y LA BULIMIA NERVIOSAS
}

\author{
Aina D. López Yáñez
}

\begin{abstract}
RESUMEN
Partiendo de la teoría de la desviación mertoniana, para la que determinadas conductas anómalas derivan de la disociación entre las aspiraciones culturalmente prescritas y el acceso a los medios correctos para llegar a ellas, resolvemos que la anorexia y la bulimia nerviosas son una respuesta típica a una situación anómica.

Primero, la belleza corporal como fin cultural presenta un fuerte carácter anómico porque es fundamentalmente un atributo físico de carácter innato que prácticamente no ofrece a los sujetos una vía para su logro. La belleza adquirida, que expresa la posibilidad de que la persona pueda actualizar ciertos rasgos de la belleza, cumple un papel muy limitado.

Segundo, el acceso a los medios de adquisición de la belleza está restringido como lo está todo sistema de objetos y servicios de consumo: económica y culturalmente.

\section{INTRODUCCIÓN. SOBRE LA OPORTUNIDAD DE UN ESTUDIO SOCIOLÓGICO DE LA ANOREXIA Y LA BULIMIA NERVIOSAS}

Hace poco más de un siglo que Durkheim defendió, en un trabajo todavía célebre, la conveniencia de un tratamiento sociológico del suicidio. La tenacidad del proyecto no deja aún hoy de causar admiración: el suicidio, consignado en los círculos intelectuales y científicos de entonces como un episodio de origen psicológico, recibía por primera vez el trato de «fenómeno social» ${ }^{1}$.

${ }^{1}$ E. Durkheim (1982), El suicidio, Ed. Akal, Madrid.
\end{abstract}


Con el tiempo, este esfuerzo investigador y teórico quedó constituido como una sólida referencia para el sociólogo, como señal de identidad de nuestra disciplina. Su notoriedad obedece precisamente a la clarividencia con que es capaz de dar cuenta del ascendente de los fenómenos sociales sobre los individuos y a lo oportuno de la correspondiente defensa de una línea de estudio fundada sobre este ordenamiento causal: la perspectiva sociológica.

Esta referencia a la progresión durkheimiana no parece gratuita en consideración al tema que nos proponemos tratar: la explicación de la anorexia y la bulimia llamadas "nerviosas». Ambas patologías han sido consideradas trastornos derivados de desórdenes alimenticios. Por lo tanto, antes que nada se examinan como enfermedades que presentan síntomas objetivos en el organismo. Sin embargo, se acepta también que su origen causal se encuentra fundamentalmente en una conducta anómala.

Desde estas páginas, sin negar la oportunidad e importancia de un enfoque médico y/o psicológico de la anorexia, pretendemos plantear un estudio sociológico del asunto, enfoque éste que, como es notorio, ha comenzado poco a poco a desarrollarse en ciertos ámbitos.

La premisa última de nuestra investigación no puede ser más básica y sencilla: la anorexia, sufrida y desarrollada por individuos concretos, es una respuesta individual significativa, cuyo contenido sólo puede ser comprendido atendiendo a su valor en el amplio y conflictivo universo simbólico formado por los hechos culturales. Buscaremos, por tanto, su sentido en el vocabulario de la cultura ${ }^{2}$ y su razón de ser en la organización social contemporánea.

\section{PUNTO DE PARTIDA: LA ANOREXIA Y LA BULIMIA NERVIOSAS DESDE LA TEORÍA DE LA ANOMIA DE ROBERT MERTON}

Como es sabido, en su análisis de la conducta desviada, Merton pretendía «descubrir cómo algunas estructuras sociales ejercen una presión definida sobre ciertas personas de la sociedad para que sigan una conducta inconformista y no una conducta conformista $»^{3}$, para lo cual distinguía entre fines («objetivos, propósitos e intereses culturalmente definidos, sustentados como objetivos legítimos por todos los individuos de la sociedad $»^{4}$ ) y medios institucionalizados (la definición, regulación y control de los modos admisibles de alcanzar esos objetivos), que no consisten en medios técnicos, sino en aquellos respaldados culturalmente. Pues bien, según la hipótesis central de Merton, determinadas

2 Parecerá que nos referimos a «una cultura»; sin embargo, no pretendemos una cosificación de la idea de cultura. En realidad, partimos de la creencia en un plexo cultural, sin negar con ello ni la existencia de aspectos genéricos al ser humano, y por lo tanto a las distintas culturas, ni el hecho cada vez más notable de la generalización de ciertos rasgos culturales característicos de áreas culturales predominantes.

${ }^{3}$ R. K. Merton (1987), Teoría y estructura sociales, Ed. FCE, México, p. 210.

${ }^{4}$ R. K. Merton (1987), p. 210. 
conductas anómalas pueden considerarse como un síntoma de la disociación entre las aspiraciones culturalmente prescritas y el acceso a los medios institucionalizados (correctos) para llegar a ellas.

Desde la consideración de este marco que subraya las consecuencias de una falta de coherencia entre la cultura y la estructura social — causa de la anomia- esbozamos nuestra explicación sociológica de la anorexia, para lo cual emprendemos un análisis de los «fines»y «medios institucionalizados» al respecto.

\section{LA BELLEZA CORPORAL COMO FIN CULTURAL: CONDICIÓN ANÓMICA}

La existencia social de un modelo estético corporal normativo más o menos definido en las sociedades occidentales actuales es un hecho reconocido por todos 5 . Incluso se ha desarrollado la reflexión y crítica públicas en torno a los modelos de belleza que han inundado los medios de comunicación de masas en los últimos tiempos, así como subrayado su influencia sobre la enfermedad de la anorexia. En este sentido, podemos afirmar que se ha emprendido un tímido abordaje sociológico del asunto: al menos se ha achacado a los patrones estéticos occidentales difundidos en los medios de comunicación de masas (a factores de índole cultural, en definitiva) la responsabilidad no sólo de la enfermedad, sino incluso también de un cierto "vaciamiento" moral colectivo como marco de ésta.

Parece entonces que el público en general es consciente de antemano de la proyección normativa de ciertos ideales formales y de que éstos no resultan inertes respecto a la formación de una actitud hacia el cuerpo - bien se trate del propio cuerpo o del cuerpo de los otros-. La posesión de un físico adecuado a los cánones (consideramos que la relación con el propio organismo se manifiesta en este contexto cultural en términos de propiedad) se percibe colectivamente como una meta, un reto hacia el cual orientar toda una serie de actividades conductoras.

Por supuesto, como toda meta socialmente propuesta, la ostentación de la belleza corporal implica una satisfacción que va más allá del cumplimiento de la norma en cuanto tal; por lo pronto, el status de quien ha logrado lo socialmente deseado y, en consecuencia, una posición social mediada por el éxito. La belleza se dibuja coronada, premiada, con la obtención de hitos culturales también normalizados, tales como pueden ser una vida social y económica grata y desenvuelta ${ }^{6} \mathrm{o}$ la facilidad en el acceso a los puestos deseados.

5 Llamamos «bello» o «belleza corporal» a aquellas expresiones que son objeto de tal consideración. No enjuiciamos la justicia u oportunidad de tal calificación.

${ }^{6}$ Leíamos en la publicidad de una empresa de productos estéticos: «el $90 \%$ de las personas con acné no encuentra empleo». No nos parece improbable este porcentaje. 
En el margen opuesto, la imposibilidad para acercar el propio cuerpo a los cánones difundidos culturalmente se sanciona como una forma de fracaso que pesa sobre el resto de las dimensiones vitales de la persona, sobre todo en el caso de las mujeres ${ }^{7}$. La belleza corporal es dibujada culturalmente como fin y, por lo tanto, su ausencia como fracaso.

Sin embargo, la belleza corporal como fin cultural presenta un fuerte carácter anómico. Partiendo de la teoría mertoniana de la anomia, deducimos que todo fin culturalmente establecido que no implica paralelamente la existencia de accesos, de uno o varios caminos cuyo recorrido conducen a la meta, es irremediablemente anómico. En tanto que las aspiraciones colectivas asumidas por el individuo encuentran un cauce de acción que posibilita su satisfacción efectiva, no generan por sí mismas una situación de angustia, de desvinculación respecto a los valores colectivos o de degradación de la identidad. Sin embargo, la belleza es fundamentalmente un atributo físico de carácter innato que prácticamente no presenta una vía segura para su logro. En este sentido ratificamos su fuerte condición anómica.

Ahora bien, sin desmentir este planteamiento, advertimos ciertas complejidades en torno a la belleza que serán fundamentales en nuestro análisis. Apuntamos la existencia de dos formas de belleza que se distinguen por la naturaleza de la instancia generadora:

- Belleza innata: es aquella que viene dada por el grado en que de forma «natural», sin intervenciones ad hoc, el físico de una persona se adecua a los patrones culturales que definen la belleza.

- Belleza adquirida (ad hoc): expresa la posibilidad de que, mediante distintas técnicas, el sujeto pueda lograr actualizar los rasgos que conforman el patrón social de la belleza.

Esta distinción nos permite comprender, de un lado, que la belleza pueda haber llegado a ser un fin cultural prioritario en las sociedades complejas -en tanto que aparenta una vía de realización que es, no obstante, mínima-. Pero también nos ayuda a ratificar el carácter anómico de la belleza como fin cultural en un sentido ahora mucho más amplio.

En el sentido ya apuntado, la actualización de los cánones de belleza física depende en mayor medida de las condiciones naturales del organismo humano que de su transformación culturalmente mediada. El acceso a la belleza lo brinda sobre todo la naturaleza. La participación humana es siempre secundaria. La belleza es un don, una fortuna otorgada caprichosamente por la naturaleza. Al individuo, sobre todo a la mujer, se le indica un fin por el que, en gran medida, no puede luchar. No hay apenas posibilidad de correspondencia entre fin y acceso al mismo.

Ha sido típico explicar la actividad femenina en distintos ámbitos como un mecanismo de compensación y autoafirmación personal destinado a compensar el fracaso en la obtención de un físico considerado «adecuado». 
En segundo lugar, en la valoración cultural de la belleza hallamos una sobreestimación de la belleza innata frente a la belleza adquirida, lo que acrecienta su carácter anómico. No sólo el margen de maniobra es estrecho; además, la belleza adquirida es infravalorada respecto a la belleza innata. Como prueba de esta afirmación apuntamos que los mecanismos de obtención de belleza (adquirida) se someten con frecuencia a un proceso de «naturalización», es decir, de ocultación de su condición ad hoc.

En tercer lugar, el carácter anómico de la belleza como fin cultural viene dado por el hecho de que el acceso a la belleza adquirida no es socialmente abierto, sino que es objeto de un proceso de estructuración, aquel que distingue asimismo al mundo del consumo. El acceso a los medios para la belleza adquirida está vedado a muchos grupos sociales.

\section{LOS MEDIOS CULTURALMENTE INSTITUCIONALIZADOS PARA LA ADQUISICIÓN DE LA BELLEZA}

Del análisis de los medios técnicos disponibles para la obtención de la belleza en relación a la autorización cultural hemos obtenido la siguiente clasificación:

- Medios legitimos para la adquisición de la belleza: En nuestra sociedad son aquellos medios que no afectan la naturaleza, que no transforman lo inscrito genéticamente, sino que sólo conducen a una «acentuación» o «normalización» de la imagen corporal sin llegar a transformar la propia. El atuendo, el maquillaje, el régimen de adelgazamiento, también el corte o «marcado» del cabello, son algunos ejemplos de esta categoría.

- Medios ilegitimos de adquisición de la belleza: Son aquellos que transforman la propia constitución corporal natural de modo definitivo. La belleza resultante no es considerada una «belleza auténtica», sino, más bien, carente de mérito. El ejemplo más sobresaliente de esta categoría nos lo ofrece la cirugía estética.

- Medios tolerados: Son aquellos medios que transforman la propia naturaleza, pero bien de modo temporal o bien de modo poco relevante. En esta categoría podemos incluir el tinte capilar o cierto tipo de tratamientos estéticos que no implican una cirugía «severa», como el «relleno» de arrugas faciales o el maquillaje semipermanente.

A pesar de ofrecer esta distinción general, entendemos que la demarcación entre medios legítimos e ilegítimos, también la influencia y contenido de los patrones corporales 8 , se presentan de modo diferencial y complejo entre los distintos grupos sociales.

${ }^{8}$ Así, por ejemplo, es tolerado que una actriz se trate los labios con colágeno, pero no así que realice esta operación una joven estudiante o la empleada de una biblioteca. 
En general, nuestra hipótesis de partida apuesta por el hecho de que los medios legítimos y tolerados se amplían conforme pasamos de zonas rurales a zonas urbanas y de un nivel socioeconómico menor a uno mayor, en virtud de la creciente influencia que el consumo ejerce entre los últimos colectivos. También advertimos de la posibilidad de existencia de áreas culturales donde la categoría de medios ilegítimos es prácticamente nula, como es el caso de Estados Unidos.

\section{EL ACCESO A LOS MEDIOS PARA LA OBTENCIÓN DE LA BELLEZA}

El acceso a los medios de adquisición de la belleza está restringido en la misma medida en que lo está todo sistema de objetos y servicios de consumo. Como es sabido, las limitaciones que reducen su acceso no son sólo de orden económico, sino también cultural. Según Baudrillard, el análisis de la lógica social del consumo "no es la de la apropiación individual del valor utilitario de los bienes y de los servicios [...] es un proceso de clasificación y de diferenciación social, en el que los objetos/signos se ordenan esta vez no sólo como diferencias significativas dentro de un código, sino como valores de status dentro de una jerarquia". En este sentido, es relevante que "el campo del consumo es un campo social estructurado, donde no sólo los bienes, sino las propias necesidades, así como los diversos rasgos de cultura, están en tránsito desde un grupo modelo, desde una minoría directiva, hacia las otras categorias sociales, a medida que tiene lugar la "promoción" relativa de éstas [...] En la cúspide (social) es donde se realiza la innovación, a fin de restaurar la distancia social. De tal modo que las necesidades de las clases medias e inferiores están siempre sujetas a un retraso, a un desfase en el tiempo y a un desfase cultural con relación a las de las clases superiores».

Bien es cierto que, quizá como medida psicológica para escapar a este modelo (quizá como mecanismo «reductor de disonancia»), se desarrolla una cierta inercia social de las necesidades. Es decir, "un cierto ajustamiento de las necesidades y aspiraciones a la situación social adquirida [...] Así, el propio proceso de producción de las aspiraciones es desigualitario, puesto que la resignación en el nivel inferior de la escala y la aspiración más libre en lo alto vienen a aumentar las posibilidades objetivas de satisfacción" ${ }^{10}$.

La adquisición a los medios de la belleza, interpretada desde este esquema, nos parece un proceso mediado por la estructura social, no ya sólo en su dimensión objetiva (mercancías), sino también en su dimensión simbólica o cultural correspondiente (a través de la educación de la sensibilidad y el gusto). Siguiendo este esquema, parece que los grupos más presionados son aquellos que menos acceso tienen a los medios de la belleza. Sin embargo, por otro

9 J. Baudrillard (1970), La sociedad de consumo, Ed. Plaza y Janés, Barcelona, p. 92.

${ }^{10}$ J. Baudrillard (1970), p. 96. 
lado, se hallaban menos presionados en los fines y están menos sensibilizados respecto a las sutilezas del contenido de la imagen.

\section{APLICACIÓN DE LA TIPOLOGÍA DE LAS ADAPTACIONES DE MERTON AL ANÁLISIS DE LA ACTITUD HACIA LA BELLEZA CORPORAL}

Una lectura de la famosa tipología de las adaptaciones de Merton facilitará tanto nuestra interpretación de la anorexia y la bulimia nerviosas como nuestra comprensión de las distintas respuestas que respecto a la belleza encontramos en nuestro medio social. A continuación ofrecemos la tipología y el relato de los distintos tipos posibles de adaptación medios-fines.

Tipología de las adaptaciones de R. Merton ${ }^{11}$

\begin{tabular}{llll}
\hline & & Fines & Medios legitimos \\
\cline { 2 - 4 } & & & \\
+ \\
Conformista
\end{tabular}

CONFORMISTA. Parece ser la característica de la conducta de la gran cantidad de sujetos que se hallan bajo la influencia de los modelos estéticos corporales. Asumen los fines, respetan y secundan los medios, y en virtud de este seguimiento obtienen resultados variables. En definitiva, tenemos aquí a un colectivo que sufre, se esfuerza, que sólo se resigna con los resultados obtenidos.

RITUALISTA. Ha aceptado la imposibilidad de alcanzar el patrón de belleza estética culturalmente difundido, incluso se distancia de él. Sin embargo, acepta y secunda religiosamente los medios para la obtención de la belleza (dietas, maquillaje, atuendo), quién sabe si por convencionalismo, por el puro apego a los trámites o con el fin de pasar desapercibido.

INNOVADOR. Su profunda asimilación de los fines, su ansiedad por acercarse al patrón de belleza corporal, le impulsan hacia el uso de medios considerados ilegítimos.

11 R. K. Merton (1987), p. 218. Se observará de inmediato que nuestra transcripción de esta tipología no es literal, sino producto de una lectura propia del texto mertoniano. 
REBELDE. Considera que el juego de la belleza es una trampa cuyo precio es la propia autoestima personal. Realiza una crítica de los patrones de belleza aceptados, pero también del papel jugado por los medios. La actitud de ciertos tipos de feminismo ha sido ésta.

RESENTIDO. En realidad, desarrolla un sentimiento de envidia que intenta ocultar con la máscara del rebelde, realizando una retirada airada y poco sincera del juego de los fines estéticos. Realiza una crítica de los modelos culturales, también de los medios, pero le mueve más el fracaso y la envidia que una conciencia íntegra. Su crítica de los modelos culturales suele ser aún más dura e intransigente que la del rebelde.

RETRAÍDO. El retraído, bajo cuyo rótulo integraríamos a aquellos que sufren la anorexia y la bulimia nerviosas, es aquel individuo que, habiendo interiorizado profundamente los fines (un patrón estético en este caso) pero sufriendo en la misma medida la imposibilidad de alcanzarlos, decide "retirarse del mundo». Es su escrupuloso afán por construirse de acuerdo a las normas lo que le orienta hacia una conducta destructiva. El anoréxico es entonces un perfeccionista, una persona que se atiene y define sobre todo a través de la norma y no tanto de la vida.

La anorexia y la bulimia nerviosas pueden entonces ser concebidas como una respuesta típica a una situación anómica en que los fines culturalmente prescritos, de un lado, son anómicos por condición y, de otro, están restringidos en el estrecho acceso que ofrecen a grupos muy específicos.

\section{UN ANÁLISIS CAUSAL Y FUNCIONAL DE LA BELLEZA CORPORAL COMO FIN CULTURAL}

¿Cabe una reflexión sociológica sobre la existencia de cierto patrón estético corporal? Nosotros pretendemos aquí sólo apuntar ciertas tendencias sociales que permiten explicar la existencia de estas referencias estéticas y, por tanto, comprender su significado. Aludimos a procesos socioculturales de gran envergadura y alcance temporal.

\subsection{La belleza en el sistema de valores occidental contemporáneo: reclusión de su hegemonía al ámbito del consumo}

Para conseguir una valoración equilibrada de los patrones estéticos en la cultura, antes que nada es preciso considerarlos en relación al resto de valores dados en un contexto sociocultural. La jerarquía de las constelaciones culturales ha ido variando según se han ido sucediendo las distintas generaciones humanas; por ejemplo, se ha apuntado a un equilibrio entre la ética y la belleza en Grecia o a la anulación de la intención puramente ornamental en el arte 
soviético. Debemos entonces desvelar la gravedad que la belleza adquiere en relación a valores tales como "lo útil», "lo meritorio»o "lo ético».

Hoy se acepta entre muchos grupos sociales que la supeditación al requerimiento de una imagen física atractiva es una condición de la vida social moderna; que lo plástico, lo bello (tal como es redefinido paulatinamente), se sobrepone a otros muchos valores tales como el honor, la sinceridad o el «carácter».

Creemos, sin embargo, que esta preponderancia de la belleza plástica no es general, es decir, que no se manifiesta como un rasgo predominante en toda expresión de la vida social contemporánea, sino que se desarrolla fragmentariamente, esto es, proyectándose de modo no distributivo. ¿Cuál es entonces el ámbito social donde la belleza ejerce su peculiar predominio? El ámbito del consumo. ¿Cuál es el objeto sobre el cual se proyecta de modo más notorio? El cuerpo humano.

Es oportuno reflexionar en torno al fundamento y alcance de esta escisión cultural. El análisis marxista del proceso de la producción social ${ }^{12}$ distingue cuatro fases del proceso productivo: producción, distribución, cambio y consumo; y apunta a que:

1) cada momento del metabolismo social es algo distinto de lo que parece;

2) los momentos se presentan como aislados, como independientes, cuando en realidad no es así, forman una totalidad orgánica.

Como consecuencia de la dinámica expuesta, el consumo parece ser una esfera específica y autónoma donde parece regir exclusivamente la voluntad individual, pues en el capitalismo el acto del consumo se manifiesta aparentemente como una situación vital aislada, libre y subjetiva. Sin embargo, sabemos de hecho que el consumo es en su contenido y desarrollo una actividad claramente referida a otros.

Desde el marco teórico proporcionado por el análisis marxista podemos explicar la extensión sólo parcial de la belleza como fin cultural; comprender, por ejemplo, el hecho de que el proceso de producción de los bienes materiales se desarrolle con frecuencia en espacios sucios y disonantes; sea sometido a un desencantador cálculo radical; manifieste una insalvable dureza estructural entre actores; pero que se objetive paradójicamente en hermosos objetos, en expresiones hermosas destinadas a acompañar o poblar el cuerpo humano. La belleza, la armonía plástica, son así invertida expresión de la reproducción social, incluso de la organización espacial de ésta. No podemos olvidar que en nuestra propia época se ha multiplicado la destrucción de ecosistemas naturales (tradicionalmente considerados hermosos) o de edificaciones históricas

12 E. Lamo de Espinosa (1981), La teoría de la cosificación, Ed. Alianza, Madrid, pp. 50-84. Aquí ofrecemos un resumen del análisis ofrecido en este texto. 
(construidas desde principios de adaptación estética y ecológica al entorno, y desarrolladas generalmente gracias al uso de materiales nobles).

En definitiva, la belleza es paradójicamente un imperativo cultural que, en su proyección, es predominante respecto a otros valores en la regulación del cuerpo y la identidad de los sujetos, pero al mismo tiempo muy marginal en esferas muy relevantes de la vida humana contemporánea.

\subsection{La "era de la imagen corporal»: capitalismo de consumo e imagen}

Reconocida la preeminencia de la belleza como valor activo en la esfera del consumo y en la consideración del cuerpo, debemos proceder a desarrollar su razón de ser. ¿Qué hay tras esta insistencia en la imagen corporal? Sin pretender aquí un estudio completo de asunto de tan gran alcance, apuntamos a la que, para nosotros, es su dimensión más relevante: aquella que muestra el ascendente del sistema económico sobre los valores culturales.

Desde la segunda guerra mundial, los sistemas de producción en el capitalismo han adquirido una dinámica de crecimiento dependiente de la creación de la demanda de objetos de consumo. A esta modalidad histórica se le ha llamado precisamente "capitalismo de consumo". ¿Qué mecanismos se han venido utilizando con el fin de promover este crecimiento de la demanda? De un lado, se han ido generalizando aquellos estudios dirigidos a averiguar qué necesidades, carencias o usos de la población eran especialmente sensibles a ser satisfechos mediante objetos de consumo derivados de los sistemas de producción correspondientes.

De otro lado, se han sofisticado indefinidamente los mensajes publicitarios, hasta el punto de que éstos han llegado a desarrollar funciones complejas. Sobre la vieja labor publicitaria consistente básicamente en intentar persuadir con carácter inmediato en el sentido deseado, el del acto de consumo, se ha generado una capacidad nueva que se va consolidando paulatinamente: la creación estandarizada a gran escala de estilos de vida y, en este sentido, la normalización de un patrón de conducta caracterizado por la expresión plástica de las identidades personales y colectivas, cuya satisfacción está mediada siempre por el mercado. Baudrillard ha llamado a esta tendencia «concentración monopolística de la producción de las diferencias» ${ }^{13}$. El resultado del proceso es que la personalidad queda mediatizada inexorablemente a la manifestación social de signos de identidad producidos en las agencias de publicidad, tanto como productos objetivos como en su dimensión significativa.

Por supuesto, esta dinámica, más que liberar al individuo al permitirle instrumentos de comunicación, le encadena, le fuerza a un diálogo y una autodefinición a través de imágenes pretextualizadas, condena al propio cuerpo a ser vehículo de expresión de sistemas significativos autoritarios. Ahora bien,

${ }^{13}$ J. BAUdRILLARD (1970), p. 129. 
este tratamiento del cuerpo como soporte de comunicación no es originario del capitalismo, sino que encuentra desarrollo en cualquier cultura, incluso en sociedades primitivas en las que el cuerpo es sostén de los signos de status social, pertenencia tribal, confesión religiosa o condición sexual e incluso marital (viudedad, noviazgo...).

¿Qué hace singular a esta dinámica de representación corporal dentro de la llamada «sociedad de consumo»? Sin duda, las mismas notas y matices que al proceso de consumo en el mundo moderno: el hecho de que su diseño es fruto de un proceso de creación racional formal (sometida a cálculo y articulada para obtener el máximo beneficio); y la ruptura radical entre su naturaleza (socialdirigida) y su apariencia (individual-electiva).

La publicidad se ha servido de la imagen como vehículo de comunicación, dadas las virtudes de ésta. La imagen hace la comunicación rápida, compleja y fuertemente expresiva. Es así que se ha producido un espectacular desarrollo de las tecnologías de la imagen y se ha incrementado el uso de éstas en distintas actividades: en la satisfacción del ocio, en la comunicación y la información, o en la enseñanza. Este proceso de crecimiento de la imagen ha ido a menudo en detrimento del experimentado por los sistemas lingüísticos, lo que ha dado lugar a duras críticas por parte de ciertos colectivos. No trataremos este asunto, aunque su mención nos permite probar que, efectivamente, se contempla una difusión creciente de la imagen sobre la palabra.

Este predominio de la imagen, esta extensión de lo plástico, una vez queda institucionalizada, es capaz de canalizar a su vez el desarrollo de la vida humana. La imagen deviene norma. De esta capacidad normativa de la imagen nos interesa especialmente su influjo sobre la formación de la identidad porque la imagen corporal, en tanto que fundamento de la identidad del sujeto, mostrará su condición fatal sobre todo en aquellos grupos en que la identidad se halla en estado crítico, fundamentalmente entre los jóvenes (cuya personalidad se halla en proceso de formación) y las mujeres (especialmente presionadas en el sentido ofrecido por una imagen dada).

Pero, sobre todo, la publicidad ha hecho uso de la belleza como mecanismo de persuasión, cuando menos, como modo de retener la atención del consumidor. En este sentido se ha afinado en el conocimiento del efecto inmediato que produce la contemplación de imágenes genéricamente bellas ${ }^{14}$. Es así que la tendencia a lo bello ha sido utilizada para la búsqueda de una respuesta en el mercado. Parece que, finalmente, la repetida concurrencia de estos modelos los ha tornado normativos ${ }^{15}$.

14 Más allá de las mediaciones introducidas por una socialización diferenciada, pueden ser identificadas ciertas gamas de notas (gustativas, visuales, auditivas, táctiles) que consiguen producir una respuesta positiva en cualquier ser humano (incluso en algunos animales).

15 No negamos que, cuando el mercado ha estado saturado de "belleza», se han buscado otros mecanismos para captar la atención y producir una «renovación» del consumidor. Sin embargo, como puede demostrarse en la práctica, la belleza ha sido el elemento más socorrido. 


\subsection{La era de la racionalización y el progreso. \\ Consecuencias sobre el patrón de belleza corporal}

Otra de las corrientes socioculturales históricas sobre la que debemos reflexionar, por su peso sobre la normalización final de la belleza corporal, es la conocida como "proceso de racionalización» (Weber). Por supuesto, la racionalización es una tendencia de gran alcance que no deja de mostrar su estrecha vinculación con el modo de producción capitalista y la cultura racionalista y analítica con que éste se desarrolló. La idea de "proceso de racionalización" intenta dar cuenta de la cada vez más acusada extensión de la racionalidad en la resolución de los conflictos y procesos humanos.

Este proceso ha sido analizado como un complejo entramado de racionalizaciones parciales que afectan de modo distinto según la realidad sobre la que operan y su sentido. En este sentido hablamos de distintas formas de racionalidad. Podemos establecer sintéticamente que, en la empresa y la actividad productiva, la racionalización se expresa en la extensión de una lógica caracterizada por la búsqueda de la maximización de los beneficios (económicos) y minimización de los costes, por el sometimiento de los procesos productivos al cálculo matemático.

En la esfera cultural, en el mundo de la vida, la racionalización se concreta en una extensión del proceder racional (de la «acción racional») en detrimento del proceder emocional o consuetudinario. Así, por ejemplo, la ética se impone a la moral tradicional, pues las costumbres dejan de ser referencia en la orientación de las relaciones sociales. Por el contrario, el comportamiento moral legítimo es aquel consecuente con el cultivo de normas abstractas que permiten una aplicación crítica, es decir, que se ayuda de la Razón en su progresión.

Esta última modalidad de racionalización ha sido la que ha caracterizado la actitud hacia lo bello en el mundo occidental. La belleza se define ahora no sobre la base del deleite espontáneo, sino en virtud de una norma estética, de un criterio ideal. Este proceso, que se presenta hoy con toda su fortaleza, fue ya vislumbrado por la filosofía. Frente a la «belleza en sí», frente al deleite que produce la observación de lo auténtico y singular, la modernidad ofrece la «belleza de acuerdo a», la consideración de la belleza como un ajuste a patrones abstractos y - normalmente- rígidos.

El contexto que posibilita la aparición de la anorexia y la bulimia nerviosas es aquel moldeado por la extensión del proceso de racionalización de la cultura a la experimentación y representación del cuerpo en una sociedad de consumo en que éste es sojuzgado desde severos parámetros estéticos que, sin embargo, no operan en otras esferas de la vida humana. 


\subsection{La funcionalidad del establecimiento de la belleza corporal como fin cultural}

Es obvio que la respuesta individual ante la imposibilidad de realizar la belleza corporal culturalmente definida probablemente dará lugar a una asimilación hostil de la propia imagen corporal y, en cierta medida, del propio cuerpo, que pasa a ser experimentado como «inadecuado envoltorio». En otro orden de cosas, apuntamos a que debería ser calculada la influencia de este aspecto en la presentación de la persona en la vida cotidiana (aunque no es éste el problema que pretendemos desarrollar aquí): cabe indicar que esta autopercepción corporal pasa con mucha probabilidad por la autoinhibición y el odiodeseo hacia el cuerpo ajeno. Y es muy probable que la no realización de la belleza corporal, tal como es definida en el contexto correspondiente, sea la situación más frecuente, dado el carácter anómico de la belleza como fin.

Desde la racionalidad material, desde la reflexión en torno a los valores humanos, se ha elevado una voz de alarma respecto a una situación en que la ansiedad y la no aceptación del propio cuerpo (incluso la imposibilidad prevista de una autoaceptación futura) parecen absurdas y graves consecuencias sobre la personalidad producidas por un trivial y vacío juego de formas. Sin embargo, la crítica, la relativa toma de conciencia no ha generado - por ejemplo- transformación alguna en los modelos estéticos corporales ${ }^{16}$. ¿Cómo explicar entonces la difusión recurrente de patrones de belleza difícilmente realizables?

A nuestro parecer, el lema de J. Baudrillard «negación de la carne, exaltación de la moda ${ }^{17}$ apunta al conjunto de motivos que explican la persistencia de la situación. El descontento general con el propio cuerpo parece proporcional al grado en que se acude al mercado para reducir la tensión correspondiente. Productos de adelgazamiento, rejuvenecimiento, maquillaje o la indumentaria adecuada — gamas de mercancías que, además, nacen y envejecen correlativamente- parecen la única salida no ya para subsanar la no adecuación al modelo estético, sino para reducir la tensión producida por la aplicación de un sistema de valores estéticos ante los cuales el cuerpo está prácticamente "predestinado", y la posibilidad de una «salvación» mediante el esfuerzo está casi por completo excluida de antemano ${ }^{18}$.

${ }^{16}$ Una prueba de ello la hallamos, en nuestro contexto más próximo, en el concurso a Miss España 1999. El concurso fue retransmitido por televisión y patrocinado por una marca de productos dietéticos. Las presentadoras del certamen — una de ellas, de delgadez extrema- se referían recurrentemente a la necesidad de perder «unos kilos de más» antes de que llegara el momento de enfundarse el traje de baño. Durante estos mismos días, tísicas modelos desfilaban los diseños de G. Armani en Milán, aunque es cierto también que estas modelos eran ridiculizadas por su tuberculoso aspecto en los informativos de cierta cadena televisiva.

${ }_{17}$ J. BAUdrillard (1970), p. 2.

18 Tampoco está de más aludir al estudio durkheimiano sobre el suicidio, en particular a los tipos de suicidio consignados por el autor como «suicidio fatalista» $\mathrm{y}$ «suicidio altruista», ambos derivados de lo excesivo del papel jugado por las representaciones sociales sobre el sujeto. En el 
Nuestra referencia a La ética protestante y el espiritu del capitalismo es evidente y se justifica porque entre la situación dibujada en el clásico weberiano y la vivenciada por anoréxicos y bulímicos hay un fondo común muy bien comprendido por Weber: la respuesta típica y normal de los individuos ante una situación fatal, preestablecida.

Es cierto que entre ambos fenómenos hay una "simetría imperfecta». Así, en el caso de la "predestinación" protestante, la ignorancia del sentido adoptado por ésta (salvación o condena) es total, mientras que en el del cumplimiento de los cánones de la belleza corporal el sentido de la "predestinación» es manifiesto. Por otro lado, la posibilidad de intervención para la adquisición de las metas, aunque mínima, existe en el caso de los patrones de belleza, y no en el caso protestante. No obstante, no hay por qué no suponer que la situación deje de conducir en ambos casos a una actividad convulsiva (cuyo objeto es el de reducir la fuerte tensión emocional ) que, como es sabido, se realiza, en el primer caso, en el ámbito profesional; en el segundo caso, mediante la «entrega" a los medios ad hoc de adquisición de la belleza en el mercado. Desde esta tensión se explica asimismo la respuesta anoréxica, sólo que ahora nos encontramos con una "huida» total de la tensión. La insatisfacción con nuestra imagen corporal resulta funcional en relación al sostenimiento o crecimiento de la demanda de objetos de consumo capaces de «revalorizar» de cualquier modo nuestro cuerpo.

De este modo, el elemento que permite explicar el sentido, la razón de ser de la extensión e intensidad que la referencia a la belleza corporal — valor profundamente anómico — ha adquirido en nuestras sociedades no es otro que el recurso a los medios para la adquisición de la belleza. Lo que permite explicar históricamente la ocupación de que es objeto la belleza corporal en nuestra sociedad no es su carácter normativo y altamente utópico (que es potencialmente común a todo programa estético), sino el papel desarrollado por los medios de adquisición de la belleza como mecanismos de disipación de un conflicto de la personalidad y, por lo tanto, como sustento y aliento de los modelos estéticos. Ahora bien, los fines son relevantes en virtud de la relevancia social efectiva, esto es, económica y social, de los medios.

primer caso, se subraya la presión ejercida sobre el individuo por una regulación excesiva de la existencia del sujeto (en este caso, podría apuntarse, a una identidad fatal e irremediable). Pero más interesante para el tema que nos trae es el segundo tipo de suicidio apuntado: el suicidio altruista supone un sujeto entregado a las representaciones sociales, invadido completamente por éstas, y, por supuesto, que se autointerpreta normativamente desde ellas. Véase E. DURKHEIM (1984), op. cit. 


\title{
BIBLIOGRAFÍA
}

Albert, E.; Mouren, M. C., y Dugas, M. (1984): «La Famille dans l'anorexie mentale masculine», en Neuropsychiatrie de l'enfance et de l'adolescence, 32, 5-6, mayo-junio, pp. 309-313.

Alonso, L. E.: «Proceso de trabajo y objeto de consumo. Apuntes para un análisis de su evolución conjunta», publicación del Departamento de Sociología de la Universidad Autónoma de Madrid.

- (1985): «Los orígenes del consumo de masas: el significado de una transformación histórica», en Estudios sobre consumo, n. ${ }^{\circ} 6$ (diciembre), pp. 11-19.

BAUdrillard, J. (1970): La sociedad de consumo, Ed. Plaza y Janés, Barcelona.

Boskind Lodahl, M. (1976): «Cinderella's Step Sisters: A Feminist Perspective on Anorexia Nervosa and Bulimia», en Signs, 2, 2, invierno, pp. 342-356.

DURKHEIM, E. (1982): El suicidio, Ed. Akal, Madrid.

LAMO DE EspinOSA, E. (1981): La teoría de la cosificación, Ed. Alianza, Madrid.

LaWrence, M. (1979): «Anorexia Nervosa. The Control Paradox», en Women's Studies International Quarterly, 2, 1, pp. 93-101.

JONES, D. (1981): "Structural Discontinuity and the Development of Anorexia Nervosa», en Sociological Focus, 14, 3, agosto, pp. 233-245.

Merton, R. K. (1987): Teoría y estructura sociales, Ed. FCE, México.

Mintz, N. E. (1982): «Bulimia: A New Perspective», en Clinical Social Work Journal, 10, 4, invierno, pp. 289-302.

Ortega y GASSET, J. (1987): "Cultura y vida», en El tema de nuestro tiempo, Ed. Revista de Occidente en Alianza Editoral, Madrid.

RutTer, M. (1980): «Disorders in Adolescence», en New Society, 52, 918, 19 junio, pp. 296297.

Turner, B. S. (1994): «Avances recientes en la Teoría del cuerpo», en REIS, n.o 68 (octubrediciembre), pp. 11-39.

Weber, M. (1985): La ética protestante y el espiritu del capitalismo, Ed. Orbis, Barcelona.

Yates, A.; Leehey, K., y Shisslak, C. M. (1983): «Running An Analogue of Anorexia?», en New England Journal of Medicine, 308, 5, 3 febrero, pp. 251-255.

\begin{abstract}
Starting out from Merton's theory of deviation, for which certain anomalous types of conduct derive from the dissociation between culturally prescribed aspirations and access to the correct methods for attaining them, we reach the conclusion that anorexia nervosa and bulimia are a typical response to an anomic situation.

Firstly, bodily beauty as a cultural aim presents a strong anomic nature because it is essentially an innate physical attribute which offers the subject practically no way of achieving it. Acquired beauty, which expresses the possibility that the individual may update certain features of beauty, plays a very limited role.

Secondly, access to the means of acquiring beauty is restricted, as is everything contained in any consumer objects and services system: both economically and culturally.
\end{abstract}

